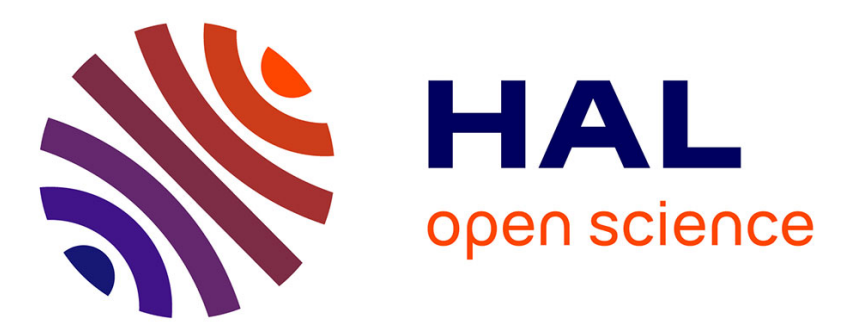

\title{
Low Thermally Activated Schottky Barrier Rectifier: A New Class of Energy Harvester
}

Xiaoqiang Gu, Simon Hemour, Ke Wu

\section{To cite this version:}

Xiaoqiang Gu, Simon Hemour, Ke Wu. Low Thermally Activated Schottky Barrier Rectifier: A New Class of Energy Harvester. 2019 IEEE International Conference on RFID Technology and Applications (RFID-TA), Sep 2019, Pisa, Italy. pp.76-79, 10.1109/RFID-TA.2019.8891999 hal-02527683

\section{HAL Id: hal-02527683 \\ https://hal.science/hal-02527683}

Submitted on 1 Apr 2020

HAL is a multi-disciplinary open access archive for the deposit and dissemination of scientific research documents, whether they are published or not. The documents may come from teaching and research institutions in France or abroad, or from public or private research centers.
L'archive ouverte pluridisciplinaire HAL, est destinée au dépôt et à la diffusion de documents scientifiques de niveau recherche, publiés ou non, émanant des établissements d'enseignement et de recherche français ou étrangers, des laboratoires publics ou privés. 


\section{Low Thermally Activated Schottky Barrier Rectifier: A New Class of Energy Harvester}

\author{
Xiaoqiang $\mathrm{Gu}$ \\ Poly-GRAMES Research Center \\ Polytechnique Montreal \\ Montreal, Canada \\ xiaoqiang.gu@polymtl.ca
}

\author{
Simon Hemour \\ IMS Laboratory, CNRS UMR 5218 \\ University of Bordeaux \\ Bordeaux, France \\ simon.hemour@u-bordeaux.fr
}

\author{
$\mathrm{Ke} \mathrm{Wu}$ \\ Poly-GRAMES Research Center \\ Polytechnique Montreal \\ Montreal, Canada \\ ke.wu@polymtl.ca
}

\begin{abstract}
Achieving high efficiency at low input power for rectifiers is crucial for realizing the Internet of Things applications and also the ultimate goal in wireless power transfer community. So far, a specially engineered backward tunnel diode has demonstrated record-breaking high efficiency at an extremely low input power range with its superior performance over any Schottky diodes. However, its commercial unavailability and limited voltage swing range have restrained vast implementation. In this work, a new class of energy harvester taking advantage of low-temperature operation conditions is proposed. Measured results present a low thermally activated Schottky diode-based rectifier can surpass opponents built with the tunnel diode on both efficiency and operating power range.
\end{abstract}

Keywords-energy harvester, low temperature, rectifier, Schottky diodes, wireless power transfer

\section{INTRODUCTION}

Urbanization is speeding up nowadays, and two-thirds of the world's population will live in urban cities by 2050 , an increase from the current 55 percent [1]. It indicates that cities will become a major battlefield for human beings to reduce energy consumption and combat climate change. In this context, the rollout of the Internet of things (IoT) technology will be a powerful weapon, as IoT is projected to realize efficient communication and sensing through batteryless techniques [2]. Wireless power transfer is thus a popular research topic around the world. Although near-field wireless power transfer has already demonstrated commercialized applications, like the wireless charging of cellphones and vehicles, far-field wireless power transfer can energize scattering unattended sensors at a large scale [3], [4]. But the main barrier of far-field wireless power transfer is limited power conversion efficiency (PCE), which is usually lower than $15 \%$ when input power is below $-30 \mathrm{dBm}$.

By far, various potent measures have been taken to leverage PCE of energy harvesters at low input power levels. The waveform manipulation of RF input power is an effective way to obtain higher PCE [5]. Combining different AC sources is also proved an attractive way to boost dc output [6], [7]. Until now, the highest PCE record holder is an energy harvester built with backward tunnel diode, which shows superior PCE performance in the low power range $(<-30$ $\mathrm{dBm})$ [8]. Tunnel diode takes advantage of quantum

This work was supported by the Natural Science and Engineering Research Council (NSERC) of Canada and IEEE MTT-S Graduate Fellowship. mechanical tunneling rather than the thermionic emission of Schottky diodes. Therefore, it successfully breaks the rectifying limitation of Schottky diodes. However, as laboratory prototypes, such tunnel diodes require sophisticated fabrication and not yet ready for mass production. Moreover, maximum tunneling current flows through when applied voltage drives the energy level of the nside conduction band equal to the energy level of the $p$-side valence band. A further increase in the applied voltage leads to a decrease in the tunneling current. This restrains the voltage swing range of tunnel diode and may further limit its rectifying performance when RF input power becomes larger. Thus, the focus of this work is on conventional Schottky diodes, which are cheap, highly accessible, and technologically mature. Since they make use of thermionic emission, this paper discusses how low-temperature conditions enhance the nonlinearity of such Schottky diodes and further result in the higher PCE of energy harvesters built with them.

\section{THEORETICAL ANALYSIS}

Schottky diodes can be characterized by SPICE parameters for the theoretical simulation. Among all the SPICE parameters, the temperature-dependent parameters are saturation current $I_{s}$, junction potential $V_{j}$, and nonlinear junction capacitance $C_{j}$ [9]. If the operating temperature of the diode is defined as $T_{\text {new }}$, the saturation current $I_{s}^{\prime}\left(T_{\text {new }}\right)$ under this temperature condition becomes:

$$
I_{S}^{\prime}\left(T_{\text {new }}\right)=I_{S} \times\left(\frac{T_{\text {new }}}{T}\right)^{\frac{X t i}{n}} e^{\left(1-\frac{T}{T_{\text {new }}}\right) \cdot \frac{E g \cdot q}{n k T}}
$$

where $X t i$ is saturation current temperature exponent, $T$ is room temperature $\left(25^{\circ} \mathrm{C}\right), n$ is ideality factor, $E_{g}$ is energy gap, $q$ is electron charge, and $k$ is Boltzmann constant. Next, the intrinsic carrier concentration $n_{i}\left(T_{\text {new }}\right)$ has to be defined first to calculate the temperature-dependent junction potential $V_{j}^{\prime}\left(T_{\text {new }}\right)$ at the new operating temperature:

$$
\begin{aligned}
& n_{i}\left(T_{\text {new }}\right)=1.45 \times 10^{10} \cdot\left(\frac{T_{\text {new }}}{T}\right)^{1.5} \times \\
&\left.e^{\left(\frac{1.115 \cdot q}{2 k T}-\frac{1.16-\frac{7.02 \times 10^{-4} \times T_{n e w}{ }^{2}}{T_{n e w}+1108}}{2 k T_{\text {new }}} q\right.}\right)
\end{aligned}
$$


$V_{j}^{\prime}\left(T_{\text {new }}\right)$ is thus expressed as:

$$
V_{j}^{\prime}\left(T_{\text {new }}\right)=V_{j} \times \frac{T_{\text {new }}}{T}+\frac{2 k T_{\text {new }}}{q} \times \ln \left(\frac{n_{i}(T)}{n_{i}\left(T_{\text {new }}\right)}\right)
$$

The temperature-dependent nonlinear junction capacitance $C_{j}^{\prime}\left(T_{\text {new }}\right)$ is calculated by:

$$
\begin{array}{r}
C_{j}^{\prime}\left(T_{\text {new }}\right)=C_{j} \times\left(1+M \times\left[1+4 \times 10^{-4} \times\left(T_{\text {new }}-T\right)-\right.\right. \\
\left.\left.\frac{V_{j}^{\prime}\left(T_{\text {new }}\right)}{V_{j}}\right]\right)
\end{array}
$$

in which $M$ is grading coefficient. Diode SMS7630 is taken as an example to show the temperature effects of the above parameters. Diode zero bias junction resistance $R_{j 0}$ which can be calculated based on $I_{s}^{\prime}$ as shown below, is also included in Fig. 1.

$$
R_{j 0}=\frac{n \cdot k \cdot T_{\text {new }}}{q \cdot I_{s}^{\prime}\left(T_{\text {new }}\right)}
$$

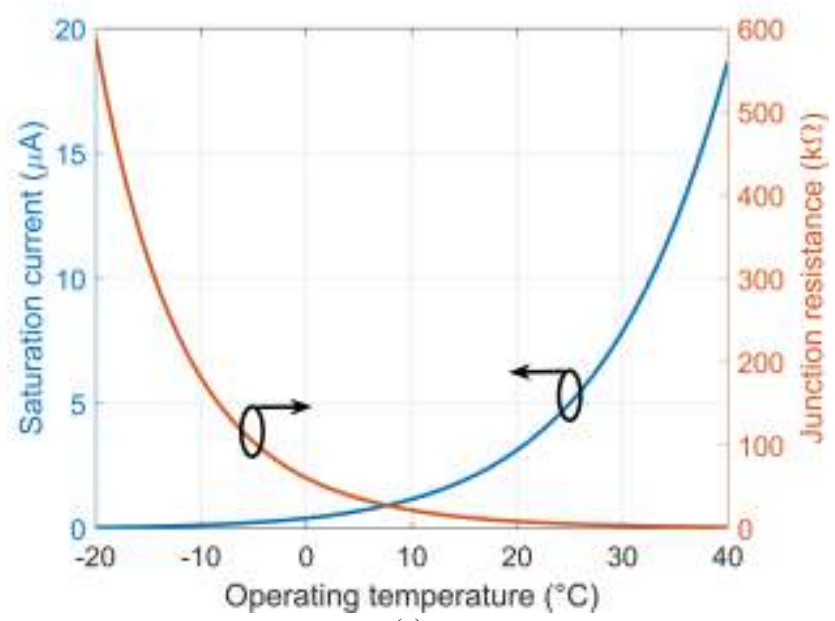

(a)

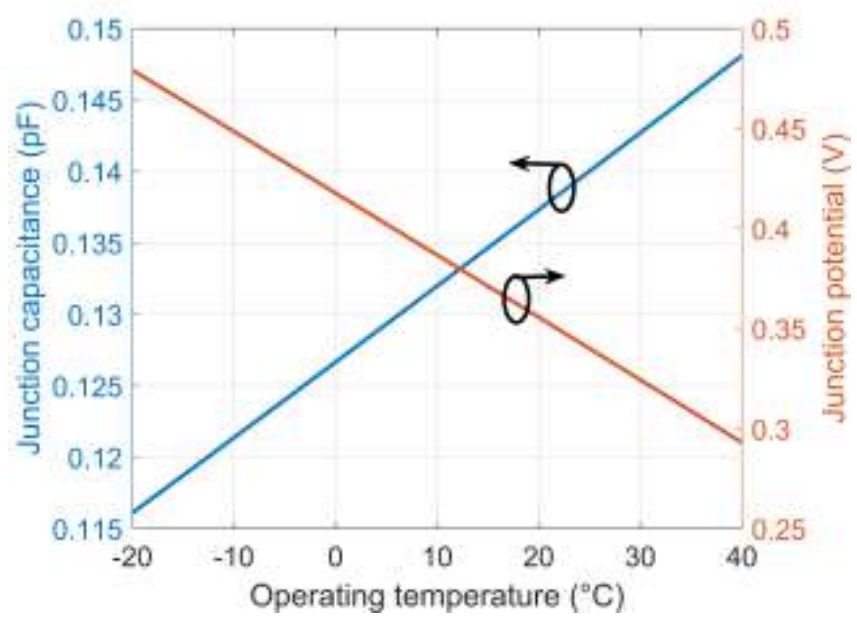

(b)
Fig. 1. Temperature response of (a) diode saturation current and zero bias junction resistance and (b) zero bias junction capacitance and junction potential in a range of $-20^{\circ} \mathrm{C}$ to $+40{ }^{\circ} \mathrm{C}$.

The temperature range is set from $-20^{\circ} \mathrm{C}$ to $+40^{\circ} \mathrm{C}$ which almost covers the range of our environment throughout the entire year. To get a clue how temperature affects the PCE performance of energy harvesters, diode RF-dc conversion efficiency $\eta_{R F d c}$ is first expressed as [10]:

$$
\eta_{R F d c}=\frac{P_{i n} \cdot \Re_{I}^{2} \cdot R_{j}^{2}}{R_{L}+R_{S}+R_{j}}
$$

in which $\Re_{I}$ is short-circuit current responsivity and associated with temperature [11]. A low temperature simultaneously lifts $R_{j 0}$ and $\Re_{I}$ up to a higher level, finally resulting in a higher $\eta_{R F d c}$ as indicated by (6).

Diode parasitic efficiency $\eta_{p}$ can be calculated by:

$$
\eta_{p}=\frac{1}{\left(1+\left(\omega \cdot C_{j}\right)^{2} \cdot R_{s} \cdot R_{j}\right)^{2}}
$$

Although $C_{j 0}$ decreases at lower temperatures, the increase of $R_{j 0}$ is a more significant factor as can be seen in Fig. 1. Thus, $\eta_{p}$ tends to be dragged down by a lower temperature. If the matching network and load resistors are optimized, PCE of the energy harvester $\left(\eta_{R F d c}\right.$ multiplying $\eta_{p}$ ) shall have an optimum temperature for peak PCE at each power level due to the opposite treads of $\eta_{R F d c}$ and $\eta_{p}$ against the temperature variations.

\section{EXPERIMENTAL VERIFICATION}

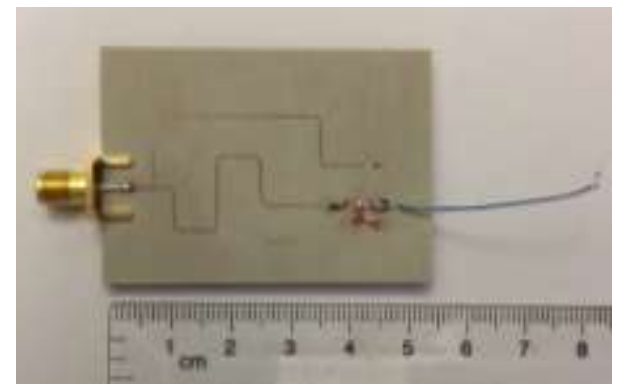

Fig. 2. Photo of an experimental prototype based on diode SMS7630.

Figure 2 shows the prototype energy harvester based on SMS7630 operating at $900 \mathrm{MHz}$. The substrate is Rogers RT/duroid 6002 with 20 mil thickness and $18 \mu \mathrm{m}$ copper cladding. The measurement setup is presented in Fig. 3. A temperature chamber (TestEquity Model 105) offers a controllable thermal environment for the test. A digital thermometer helps better read the inner temperature of the chamber. As can be seen in Fig. 1, temperature variations induce the change of diode junction resistance and capacitance, affecting diode impedance. To maintain the same input power injecting into the energy harvester under various thermal conditions, power compensation is required due to the mismatch loss of the untunable matching network. Therefore, a vector network analyzer (VNA) is adopted in the measurement, which can simultaneously measure S11 and 
offer RF power for the energy harvester. The use of VNA here has simplified measurements considering the necessary power compensation. Optimum load resistor of the energy harvester is considered the same as the diode zero bias junction resistance in a low power range. Under different thermal conditions, a tunable resistor keeps the energy harvester with an optimum loading. A multimeter reads dc output voltage of the energy harvester.

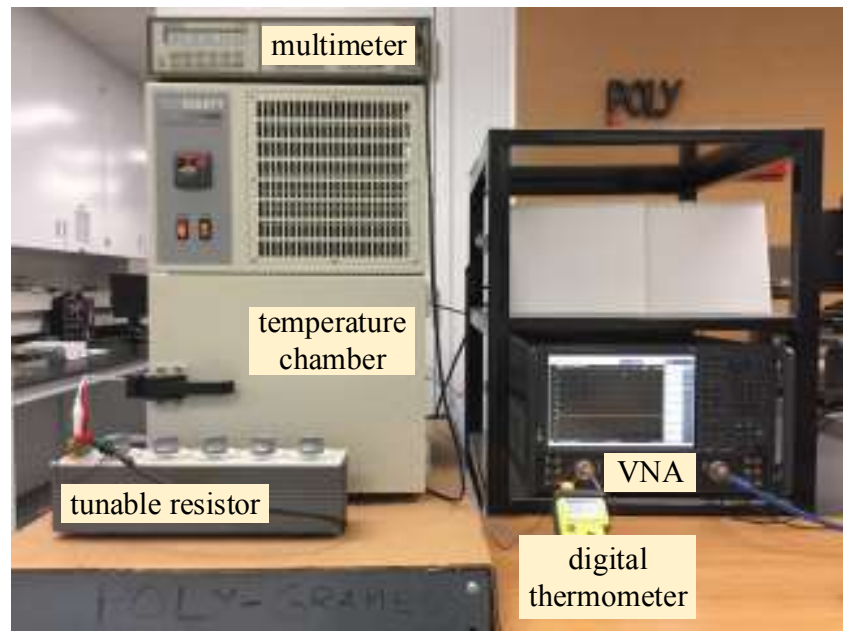

Fig. 3. Photo of the measurement setup.

Three power levels $(-40 \mathrm{dBm},-30 \mathrm{dBm}$, and $-20 \mathrm{dBm})$, are investigated and the temperature is swept from $-20{ }^{\circ} \mathrm{C}$ to $+40^{\circ} \mathrm{C}$ with an increment of $5{ }^{\circ} \mathrm{C}$. The optimum temperatures at each power level of the energy harvester are captured (Table I), which is consistent with the previous theoretical analysis. Compared to the energy harvester operating at room temperature $\left(25^{\circ} \mathrm{C}\right)$, PCE enhancements are observed which is more obvious at a lower input power level $(-40 \mathrm{dBm})$. Our measured peak PCE results are compared with some state-ofthe-art works with advanced performance [8], [11, 12] in Fig. 4. Measured results of this work show superior performance than other Schottky diode-based rectifiers including VDI ZBD diode. Backward tunnel diode still demonstrates its unbeatable performance in the low power range $(<-30 \mathrm{dBm})$. Due to its limited voltage swing range, its PCE performance is surpassed by common commercial Schottky diode-based energy harvester operating at their optimum temperatures. Improvements to this work are still possible. For example, multi-stage matching networks can be used to reduce insertion loss. Diodes with lower parasitics are also helpful to enhance PCE performance.

TABLE I

OPTIMUM TEMPERATURES OF THE ENERGY HARVESTER AND PCE IMPROVEMENTS OVER ROOM TEMPERATURE

\begin{tabular}{|c|c|c|}
\hline & Optimum Temperatures & PCE Improvements \\
\hline$-20 \mathrm{dBm}$ & $5{ }^{\circ} \mathrm{C}$ & $6 \%$ \\
\hline$-30 \mathrm{dBm}$ & $10^{\circ} \mathrm{C}$ & $6 \%$ \\
\hline$-40 \mathrm{dBm}$ & $5{ }^{\circ} \mathrm{C}$ & $27 \%$ \\
\hline
\end{tabular}

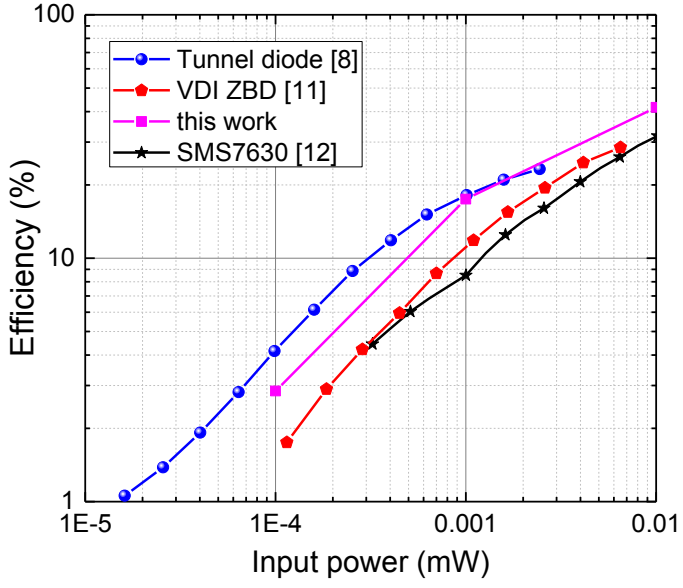

Fig. 4. Comparison of measured PCE results with other state-of-the-art works.

\section{CONCLUSION}

This work demonstrates an energy harvester based on low thermally activated Schottky diode can outperform the opponent built with the backward tunnel diode. Optimum temperatures for the energy harvester are acquired in a range of $5{ }^{\circ} \mathrm{C}$ to $10^{\circ} \mathrm{C}$ for the SMS7630-based energy harvester. Further improvements of matching network design and proper selection of low-parasitic diode are believed beneficial for such low-power energy harvesters. This work also serves as a reminder that thermal effects on any Schottky diode-based circuits need to be carefully studied to ensure their great performance and high reliability.

\section{ACKNOWLEDGMENT}

The authors would like to express gratitude to the technical support team of Poly-GRAMES Research Center, who are J. Gauthier, D. Dousset and T. Antonescu.

\section{REFERENCES}

[1] United Nations Population Division, "2018 revision of world urbanization prospects," United Nations Department of Economic and Social Affairs, Population Division: New York, NY, USA, May 2018.

[2] K. E. Jeon, J. She, J. Xue, S.-H. Kim, and S. Park, "luXbeacon-A Batteryless Beacon for Green IoT: Design, Modeling, and Field Tests," IEEE Internet Things J., to be published, doi: 10.1109/JIOT.2019.2894798.

[3] S. Hemour, X. Gu, and K. Wu, "Efficiency of Rectenna," in Recent Wireless Power Transfer Technologies via Radio Waves, N. Shinohara, Ed., ed: River Publishers, 2018, pp. 95-132.

[4] X. Gu, S. Hemour, and K. Wu, "Enabling Far-Field Ambient Energy Harvesting Through Multi-Physical Sources," in Proc. Asia Pac. Microw. Conf., Kyoto, Japan, Nov. 2018, pp. 1-3.

[5] B. Clerckx and E. Bayguzina, "Low-complexity adaptive multisine waveform design for wireless power transfer," IEEE Antennas Wireless Propag. Lett., vol. 16, pp. 2207-2210, May 2017.

[6] X. Gu, S. Hemour, L. Guo, and K. Wu, "Integrated Cooperative Ambient Power Harvester Collecting Ubiquitous Radio Frequency and Kinetic Energy," IEEE Trans. Microw. Theory Tech., vol. 66, no. 9, pp. 4178-4190, Sep. 2018.

[7] X. Gu et al., "Hybridization of Integrated Microwave and Mechanical Power Harvester," IEEE Access, vol. 6, pp. 13921-13930, Mar. 2018. 
[8] C. Lorenz et al., "Breaking the efficiency barrier for ambient microwave power harvesting with heterojunction backward tunnel diodes," IEEE Trans. Microw. Theory Tech., vol. 63, no. 12, pp. 4544 4555, Dec. 2015.

[9] P. Antognetti and G. Massobrio, Semiconductor Device Modeling With SPICE. New York, NY, USA: McGraw-Hill, 1998.

[10] S. Hemour et al., "Towards low-power high-efficiency RF and microwave energy harvesting," IEEE Trans. Microw. Theory Tech., vol. 62, no. 4, pp. 965-976, Apr. 2014.

[11] C. Lorenz, S. Hemour, and $\mathrm{K}$. Wu, "Physical mechanism and theoretical foundation of ambient RF power harvesting using zerobias diodes," IEEE Trans. Microw. Theory Tech., vol. 64, no. 7, pp. 2146-2158, Jul. 2016.

[12] C. Song, Y. Huang, J. Zhou, J. Zhang, S. Yuan, and P. Carter, "A highefficiency broadband rectenna for ambient wireless energy harvesting," IEEE Trans. Antennas Propag., vol. 63, no. 8, pp. 34863495, Aug. 2015. 